\title{
Epidemiological Assessment of Seasonal Diarrhoea Cases in Flood Prone Chiga Ward, Lake Victoria Basin, Kenya
}

\author{
Redemptah A Yeda ${ }^{1 *}$, Peter Omemo ${ }^{2}$, Nancy Makunda ${ }^{3}$, Eric Okello ${ }^{4}$ and George Ayodo ${ }^{1,5}$ \\ ${ }^{1}$ Department of Public Health, Jaramogi Oginga Odinga University of Science and Technology, Kenya \\ ${ }^{2}$ Department of Public Health, Maseno University, Kenya \\ 3Jaramogi Oginga Odinga Teaching and Referral Hospital, Kenya \\ ${ }^{4}$ School of Mathematics, University of Nairobi, Kenya \\ ${ }^{5}$ Kenya Medical Research Institute, Kenya
}

*Corresponding authors: Redemptah A Yeda, Jaramogi University of Science and Technology, Kenya, E-mail: Redemptah.yeda@usamru-k.org

Received: 14 Jun, 2019 | Accepted: 15 Jul, 2019 | Published: 22 Jul, 2019

Citation: Yeda RA, Omemo P, Makunda N, Okello E, Ayodo G (2019) Epidemiological Assessment of Seasonal Diarrhoea Cases in Flood Prone Chiga Ward, Lake Victoria Basin, Kenya. J Epidemiol Public Health Rev 4(2): dx.doi.org/10.16966/2471-8211.171

Copyright: (C) 2019 Yeda RA, et al. This is an open-access article distributed under the terms of the Creative Commons Attribution License, which permits unrestricted use, distribution, and reproduction in any medium, provided the original author and source are credited.

\begin{abstract}
Introduction: In western Kenya, around Lake Victoria basin, diarrhoea is generally common among adults due to the high prevalence of immunecompromised persons.
\end{abstract}

Objective: To assess seasonal diarrhoea cases in flood prone Chiga ward Lake Victoria basin, Kenya between 2012 to 2016.

Method: Health records of clinically-diagnosed and treated diarrhoea cases in the period between 2012 to 2016 were extracted from the registers at Chiga Health Centre and then stored electronically in an excel format. Monthly average rainfall in millimeters for the period of 2012 to 2016 was collected from TuTiempo.net for the Lake Victoria basin. Data transformation and analysis for health records and rainfall data were performed using R software (version 3.4.2).

Result: A total of 774 cases of diarrhoea were treated at Chiga Health Centre between 2012 and 2016. More than two-third (67.3\%) of the cases were adults ( $\geq 18$ years) with a standard deviation of (16.52) and (IQR: 25.0-49.0). followed by older children ( $\geq 5$ years) with (SD=1.94) and (IQR: 7.0-10.0). Adults reported high cases of diarrhoea compared to older children across all the years from 2012 to 2016 ; this implies that adolescent group reported low cases of diarrhoea. More than half (59.9\%) of the cases were females while $40.1 \%$ were males. Percentage distribution of the treated cases followed a seasonal pattern with peaks being observed from quarter two and quarter four of each year.

Conclusion: From the findings of this study, age and seasonality are key epidemiological variables for the prevention and control of a seasonal outbreak of diarrhoea. Provision of portable clean water to the households may reduce the prevalence of diarrhoea, especially among residents in Chiga ward.

Keywords: Epidemiological assessment; Seasonal diarrhoea

\section{Introduction}

Diarrhoea is a symptom of infections caused by a host of bacterial, viral and parasitic organisms, most of which are spread by fecescontaminated water. Rotavirus and Escherichia coli are the two most common etiological agents of moderate-to-severe diarrhoea in low-income countries [1]. In western Kenya, diarrhoea is generally common among adults due to the high prevalence of immunecompromised persons [2] Chiga ward in the Lake Victoria basin, western Kenya experience prolonged drought during the year and short periods of widespread flooding. Projects show that the Lake Victoria basin will continue to experience flooding in the future due to climate change and induced rainfall patterns. We performed an epidemiological assessment of seasonal diarrhoea cases in flood prone Chiga ward in the Lake Victoria Basin (LVB), Kenya for the period between 2012 to 2016 with the aim of informing policy on prevention and control of diarrhoea in the region.

\section{Materials and Methods}

Chiga health center is located in Kisumu County on the edge of Lake Victoria, Kenya. The area lies between longitudes of $42^{\circ} 50 \mathrm{E}$ and $43^{\circ} 20 \mathrm{E}$ and latitudes $9^{\circ} 40 \mathrm{~N}$ and $12^{\circ} 30 \mathrm{~N}$. The health center serves a population of over ten thousand residents. The main occupation of the residents is mainly fishing and subsistence farming. Data for diarrhoea cases were extracted from medical records. Data collected showed all the demographics of the patient in addition to their place of origin. The data was mainly on diarrhoea cases diagnosed and treated by the resident clinical officers at the Chiga Health Center in the period between 2012 to 2016. Monthly average rainfall (millimeters) 
per month for the Lake Victoria basin for the period 2012 to 2016 was collected from TuTiempo.net.

Ethical approval to conduct the study was obtained from the Jaramogi Oginga Odinga Teaching and Referral Hospital Ethical Review Committee.

\section{Data management and analysis}

The extracted data was stored electronically in an excel format. Data transformation and analysis for health records and rainfall data were performed using $\mathrm{R}$ software (version 3.4.2) to generate descriptive epidemiological information. Fisher exact test was used to show a significant relationship between the age group of the subjects and period of the event.

\section{Results}

There were 774 confirmed diarrhoea cases at Chiga Health Centre between 2012 and 2016. More than two-thirds (67.3\%) of the diarrhoea cases were adults ( $\geq 18$ years) followed by older children $(>5$ years). The mean age for adults' patients was 38.7 years old, Standard Deviation (SD) of 6.52 and the median age was 35.0 years, InterQuartile Range (IQR) of 25.0-49.0. In addition, the mean age for older children was 8.7 years $(\mathrm{SD}=1.94)$ and the median age was 9 years, IQR (7.0-10.0). For the adolescent group ( $\geq 14$ years) the mean age was 15.2 years $(\mathrm{SD}=1.54)$, median age of 15 years, IQR $(14.0-17.0)$. Over half (59.9\%) of the patients were females compared to $40.1 \%$ who were males (Table 1).

The patient information was retrieved from the health records where we could find the name, age, sex and place of origin. These records did not include children under five years since such data are captured elsewhere at the Maternal and Child Clinic (MCH).
Diarrhoea was high among adults $(\mathrm{n}=521)$, followed by older children (174), and diarrhoea among adolescents was low (79) cases as shown in table 1 below.

The data was also analyzed per quarter and percentage distribution for diarrhoea cases was calculated quarterly across age groups for all the years between 2012 and 2016 (Table 2).

Adults reported high cases of diarrhoea compared to older children across all the years from 2012 to 2016; this implies that the adolescent group reported low cases of diarrhoea. There was a significant relationship between the age group of the subjects and period of the event in the year $2016(\mathrm{p}<0.05)$. However, the rest of the years had an insignificant relationship between age group and the period of the event.

Table 3 shows descriptive statistics of rainfall in millimeters from the year 2012 to 2016 . The year 2012 recorded the highest average amount of rainfall (median $=379.6 \mathrm{~mm}, \mathrm{IQR}=199.0-559.7$ ) compared to the rest while the least average amount of rainfall was reported in the year 2016 (median=26.3 mm, IQR=3.1-121.4).

\section{Epidemiological Seasonality of Diarrhoea}

Figures 1-5 shows a five-year trend analysis of diarrhoea and rainfall. The year 2012 rainfall and diarrhoea cases were high in the second quarter of the year and the same was experienced in the year 2013. In the year 2014 and 2016, the number of diarrhoea cases increased in the third quarter of the year. The year 2015 showed high diarrhoea cases in the second quarter and the fourth quarter.

As the rainfall level increases diarrhoea level also increases across the study period especially for the adults followed by the older children.

Table 1: Demographic information.

\begin{tabular}{|c|c|c|c|c|c|c|}
\hline & $\mathbf{N}$ & Percent & Mean age & SD & Median & IQR \\
\hline \multicolumn{7}{|l|}{ Age } \\
\hline Older children & 174 & 0.225 & 8.7 & 1.94 & 9 & $7.0-10.0$ \\
\hline Adolescent & 79 & 0.102 & 15.2 & 1.54 & 15 & $14.0-17.0$ \\
\hline Adult & 521 & 0.673 & 38.7 & 6.52 & 35 & $25.0-49.0$ \\
\hline \multicolumn{7}{|l|}{ Sex } \\
\hline Female & 464 & 59.9 & & & & \\
\hline Male & 310 & 40.1 & & & & \\
\hline
\end{tabular}

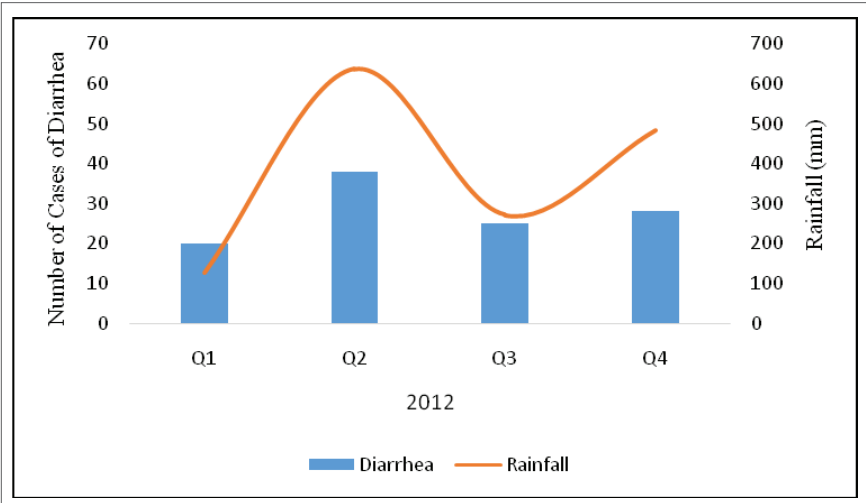

Figure 1: Quarterly rainfall and reported diarrhoea cases in Chiga Health Centre in the year 2012.

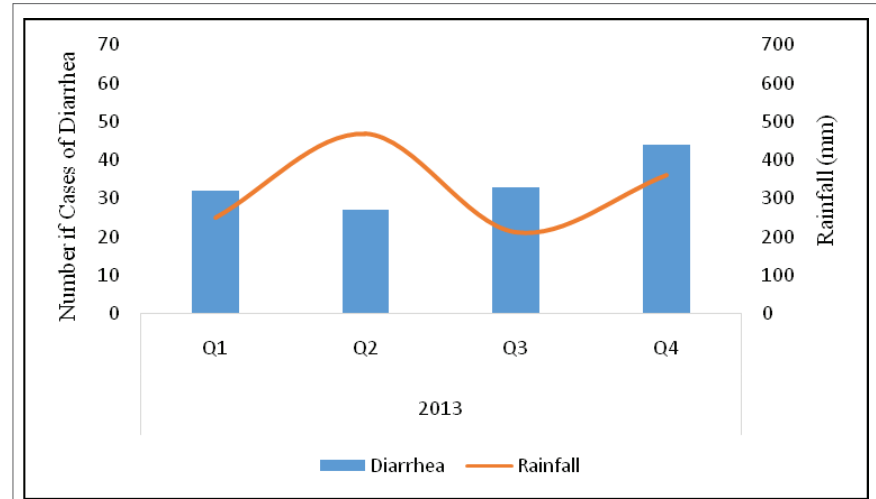

Figure 2: Quarterly rainfall and reported diarrhea cases in Chiga Health Centre in the year 2013. 
Figure 1 below shows an overlay graph of diarrhoea cases and precipitation per quarter in the year 2012.

Figure 2 below shows an overlay graph of diarrhoea cases and precipitation in the year 2013 presented per quarter.

Figure 3 below shows an overlay graph of diarrhoea cases and precipitation in the year 2014 presented per quarter.

Figure 4 below shows an overlay graph of clinically confirmed diarrhoea cases and precipitation against period for the year 2015.

Figure 5 below shows an overlay graph of clinically confirmed diarrhoea cases and precipitation against period for the year 2016.

\section{Discussion}

In this current study, the highest incidence of diarrhoea was observed among adults ( $\geq 18$ years), followed by older children. A similar picture was observed by [3] where the highest incidence was observed among persons aged 18-39 years, followed by children. However, these results differ with findings by [4] that found diarrhoea higher among children (under five years) than adults. The quarterly distribution of patients with diarrhoea across all the years (2012-2016) was highest in the adult population compared to either older children or adolescents. However, in the adolescents' population, there were lower quarterly distributions than the older children across almost all the years between 2012 and 2016 except in quarter 3 of 2013, quarter 2 of 2014 and quarter 1 of 2016 where adolescents recorded higher proportions of diarrhoea than the older children.

Table 2: Quarterly distribution of diarrhoea cases per age group.

\begin{tabular}{|c|c|c|c|c|c|}
\hline Year & Period & Children & Adolescents & Adults & p-value ${ }^{a}$ \\
\hline \multirow{4}{*}{2012} & Q1 & $2(10.0 \%)$ & $0(0.0 \%)$ & $18(90.0 \%)$ & 0.432 \\
\hline & Q2 & $9(23.7 \%)$ & $4(10.5 \%)$ & 25 (65.8\%) & \\
\hline & Q3 & 5 (20.0\%) & $3(12.0 \%)$ & 17 (68.0\%) & \\
\hline & Q4 & 4 (14.3\%) & $1(3.6 \%)$ & 23 (82.1\%) & \\
\hline \multirow{4}{*}{2013} & Q1 & $8(25.0 \%)$ & $3(9.4 \%)$ & 21 (65.6\%) & 0.118 \\
\hline & Q2 & $8(29.6 \%)$ & 1 (3.7\%) & $18(66.7 \%)$ & \\
\hline & Q3 & $4(12.1 \%)$ & $6(18.2 \%)$ & $23(69.7 \%)$ & \\
\hline & Q4 & 7 (15.9\%) & $1(2.3 \%)$ & 36 (81.8\%) & \\
\hline \multirow{4}{*}{2014} & Q1 & 11 (28.9\%) & 3 (7.9\%) & $24(63.2 \%)$ & 0.168 \\
\hline & Q2 & 3 (9.4\%) & $6(18.8 \%)$ & 23 (71.9\%) & \\
\hline & Q3 & $16(30.2 \%)$ & $8(15.1 \%)$ & 29 (54.7\%) & \\
\hline & Q4 & $8(22.9 \%)$ & 2 (5.7\%) & 25 (71.4\%) & \\
\hline \multirow{4}{*}{2015} & Q1 & $11(27.5 \%)$ & 5 (12.5\%) & $24(60.0 \%)$ & 0.645 \\
\hline & Q2 & 15 (31.9\%) & $8(17.0 \%)$ & $24(51.1 \%)$ & \\
\hline & Q3 & $14(27.5 \%)$ & $3(5.9 \%)$ & 34 (66.7\%) & \\
\hline & Q4 & 15 (27.8\%) & $8(14.8 \%)$ & 31 (57.4\%) & \\
\hline \multirow{4}{*}{2016} & Q1 & 5 (11.4\%) & $6(13.6 \%)$ & $33(75.0 \%)$ & 0.019 \\
\hline & Q2 & $5(10.6 \%)$ & $5(10.6 \%)$ & 37 (78.7\%) & \\
\hline & Q3 & $12(20.0 \%)$ & 5 (8.3\%) & $43(71.7 \%)$ & \\
\hline & Q4 & $12(46.2 \%)$ & 1 (3.8\%) & 13 (50.0\%) & \\
\hline
\end{tabular}

Note: ap-values are based on Fisher's exact test since 1 or more of the cells had an expected frequency of five or less.
Table 3: Rainfall Distribution.

\begin{tabular}{|c|c|c|c|c|c|}
\hline Year & N & Mean & SD & Median & IQR \\
\hline 2012 & 12 & 379.3 & 225.51 & 376.9 & $199.0-559.7$ \\
\hline 2013 & 12 & 322.8 & 115.7 & 305.8 & $231.0-414.6$ \\
\hline 2014 & 12 & 252 & 67.25 & 222.1 & $214.0-290.1$ \\
\hline 2015 & 12 & 251.6 & 130.92 & 208.3 & $164.0-339.3$ \\
\hline 2016 & 12 & 62.2 & 91.72 & 26.3 & $3.1-121.4$ \\
\hline
\end{tabular}

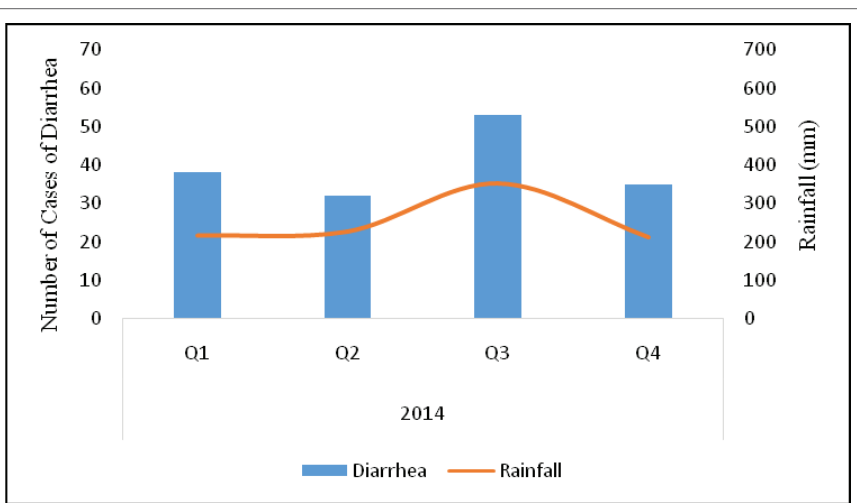

Figure 3: Quarterly rainfall and reported diarrhoea cases in Chiga Health Centre for the year 2014.

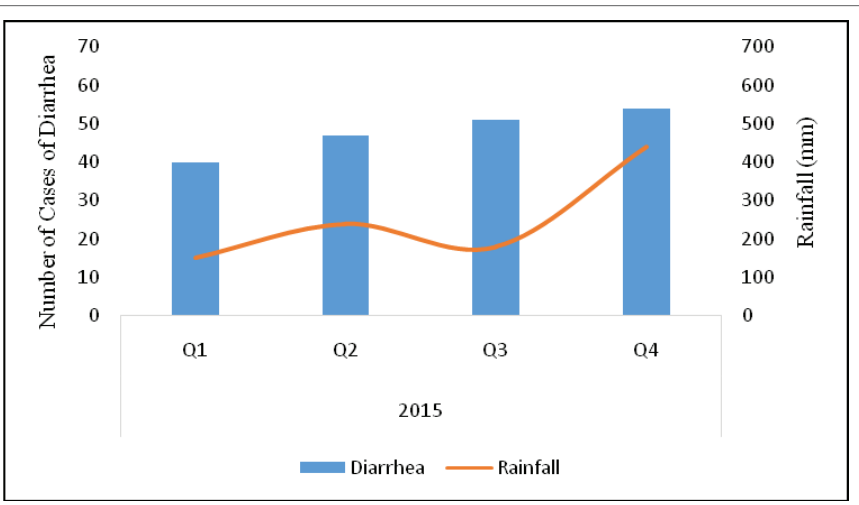

Figure 4: Quarterly rainfall and reported diarrhoea cases in Chiga Health Centre for the year 2015.

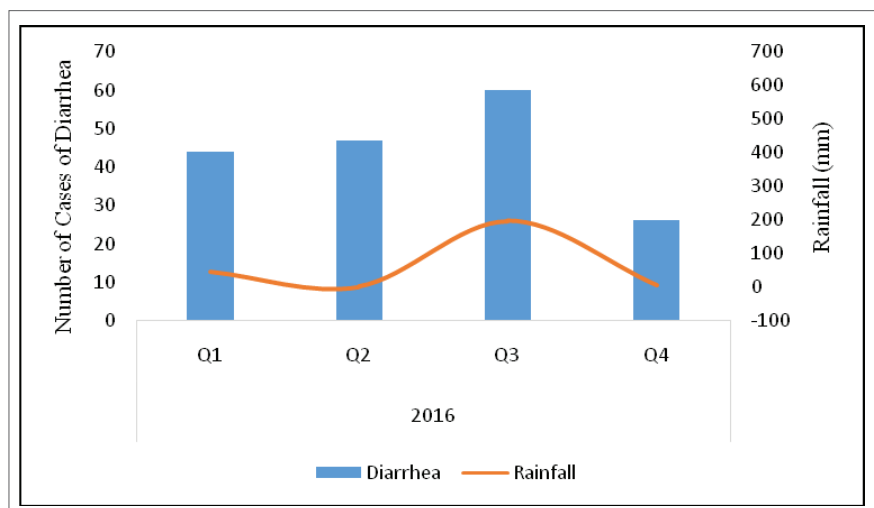

Figure 5: Quarterly rainfall and reported diarrhea cases in Chiga Health Centre for the Year 2016. 
The present study examined the seasonal patterns of crude diarrhoea disease counts at Chiga ward. Generally, the diarrhoea epidemiology followed rainfall pattern. This observation agrees with findings by [5]. Unlike the studies by [6], which revealed two annual diarrhoea peaks, the current study detected only one peak. In the current study, the diarrhoea incidence followed rainfall peaks, but no pattern was observed between the quarterly peaks and diarrhoea incidence. Observation of the cases shows that fewer cases were attended to during dry season compared to the rainy season. This observation is consistent with the findings of [7-9].

\section{Conclusion}

From the findings of the current study, age and seasonality are key epidemiological variables for prevention and control of a seasonal outbreak of diarrhoea in Chiga area.

\section{Recommendations}

The low prevalence in older children and adolescent seen in the current study require an investigation which specifically compares the proportions of the different population groups (children, adolescents, adults) with the proportion of diarrhoea cases in these groups. Provision of clean domestic water to the households may reduce the prevalence of diarrhoea, among the residents of Chiga ward.

\section{References}

1. Fischer Walker CL, Perin J, Aryee MJ, Boschi-Pinto C, Black RE (2012) Diarrhea incidence in low-and middle-income countries in 1990 and 2010: a systematic review. BMC Public Health 12: 220.
2. Feikin DR, Audi A, Olack B, Bigogo GM, Polyak C, et al. (2010) Evaluation of the optimal recall period for disease symptoms in home-based morbidity surveillance in rural and urban Kenya. Int J Epidemiol 39: 450-458.

3. Bandyopadhyay S, Kanji S, Wang L (2012) The impact of rainfall and temperature variation on diarrheal prevalence in Sub-Saharan Africa. Applied Geography 33: 63-72.

4. Gong XH, Wu HY, Li J, Xiao WJ, Zhang X, et al. (2018) Epidemiology, aetiology and seasonality of infectious diarrhoea in adult outpatients through active surveillance in Shanghai, China, 2012-2016: A crosssectional study. BMJ Open 8: e019699.

5. Lamberti LM, Fischer Walker CL, Black RE (2012) Systematic review of diarrhoea duration and severity in children and adults in low and middle income countries. BMC Public Health 12: 276.

6. Tornheim JA, Manya AS, Oyando N, Kabaka S, O'Reilly CE, et al. (2010) The epidemiology of hospitalization with diarrhea in rural Kenya: the utility of existing health facility data in developing countries. Int J Infect Dis 14: e499-e505.

7. Walker CL, Black RE (2010) Diarrhoea morbidity and mortality in older children, adolescents and adults. Epidemiol Infect 138: 12151216.

8. World Health Organization (2014) Preventing diarrhoea through better water, sanitation and hygiene: Exposures and impacts in lowand middle-income countries. Geneva, Switzerland 1-32.

9. Wu J, Yunus M, Streatfield PK, Emch M (2014) Association of Climate variability and childhood diarrhoeal diseases in rural Bangladesh, 2000-2006. Epidemiol Infect 142: 1859-1868. 